\title{
Dietary risk factors for the development of insulin resistance in adolescent girls: a 3-year prospective study
}

James White ${ }^{1, *}$, Russell Jago ${ }^{2}$ and Janice L Thompson ${ }^{2}$

${ }^{1}$ Centre for the Development and Evaluation of Complex Interventions for Public Health Improvement, School of Medicine, Cardiff University, Heath Park, Cardiff CF1 4 4YS, UK: ${ }^{2}$ Centre for Exercise, Nutrition \& Health

Sciences, School for Policy Studies, University of Bristol, Bristol, UK

Submitted 24 May 2012: Final revision received 10 September 2012: Accepted 14 September 2012: First published online 19 November 2012

\begin{abstract}
Objective: Identifying risk factors for insulin resistance in adolescence could provide valuable information for early prevention. The study sought to identify risk factors for changes in insulin resistance and fasting blood glucose levels.

Design: Prospective cohort of girls participating in the National Heart, Lung, and Blood Institute Growth and Health Study.

Setting: USA.

Subjects: Adolescent girls ( $n$ 774) assessed at the ages of 16-17 and 18-19 years.

Over a 3-year period, measurements of fasting blood glucose and insulin and serum cotinine were taken, and dietary intake ( $3 \mathrm{~d}$ food diary), smoking status and physical activity levels were self-reported.

Results: Improvements in homeostasis model assessment of insulin resistance (HOMA-IR) were associated with increases in the percentage of energy intake from polyunsaturated fats $(\beta=-3 \cdot 33,95 \%$ CI $-6 \cdot 28,-0 \cdot 39, P=0.03)$ and grams of soluble fibre $(\beta=-5 \cdot 20,95 \% \mathrm{CI}-9 \cdot 81,-0 \cdot 59, P=0 \cdot 03)$ between the ages of 16-17 and 18-19 years; with similar findings for insulin. Transitioning into obesity was associated with an increase in insulin $(\beta=6 \cdot 34,95 \%$ CI $2 \cdot 78,9 \cdot 91$, $P<0 \cdot 001)$ and HOMA-IR $(\beta=28 \cdot 77,95 \%$ CI $8 \cdot 13,49 \cdot 40, P=0 \cdot 006)$. Serum cotinine concentrations at 16-17 years, indicating exposure to tobacco, were associated with large increases $(\beta=15 \cdot 43,95 \%$ CI $6 \cdot 09,24 \cdot 77, P<0 \cdot 001)$ in fasting blood glucose concentrations.

Conclusions: Increases in the percentage of energy from polyunsaturated fat and fibre, and avoidance of excess weight gain and tobacco exposure, could substantially reduce the risk of insulin resistance in late adolescence.
\end{abstract}

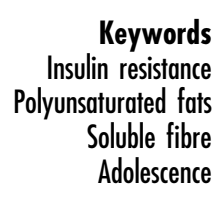

In the past 30 years, the worldwide prevalence of type 2 diabetes mellitus (T2DM) has increased substantially ${ }^{(1)}$ with an accompanying decrease in the age of onset, especially in black US women ${ }^{(2)}$. In the SEARCH for Diabetes in Youth Study, the incidence of diabetes mellitus was 24.3 (per 100000 person-years) in 2002-2003, with T2DM most common in African Americans (19.4\%) and American Indians (49.4\%) aged 15-19 years ${ }^{(3)}$. Although recent evidence suggests that the increase in childhood obesity might be abating in the $\mathrm{USA}^{(4)}$ and some parts of Europe ${ }^{(5,6)}$, the prevalence of obesity in childhood still remains high ${ }^{(7)}$ and is likely to fuel an increase in the prevalence of impaired fasting glucose (IFG) and T2DM in the future. To curb this potential increase, it is necessary that effective means of limiting the number of adolescents who become insulin resistant are identified.

Excess body fat is the primary risk factor for insulin resistance $^{(8)}$ and T2DM in youth ${ }^{(9,10)}$, but other factors have also been hypothesized. Frequent consumption of dietary fibre has been associated with a reduced risk of insulin resistance in two prospective cohorts with young adults $^{(11,12)}$. For example, one 10-year cohort reported an inverse association between dietary fibre and fasting insulin and $2 \mathrm{~h}$ insulin levels after provision of a glucose supplement ${ }^{(11)}$. A meta-analysis of nine cohort studies has also suggested that fibre from cereals may be particularly important in reducing the risk of T2DM in adults ${ }^{(13)}$. Beneficial effects of diets high in monounsaturated ${ }^{(14)}$ and polyunsaturated fats ${ }^{(15,16)}$ have also been reported in adults with T2DM. In a 14-year prospective cohort of 84204 middle-aged women, a $5 \%$ increase in the intake of polyunsaturated fat was associated with a large reduction in the incidence of $\mathrm{T} 2 \mathrm{DM}$ (relative risk $=0.63$, $95 \%$ CI $0.53,0 \cdot 76)^{(16)}$. However, support for the effect of monounsaturated and polyunsaturated fats has not been universal $^{(17)}$, in part due to the inconsistent adjustment for the effect of different types of fats. 
Other factors linked to the development of insulin resistance in adults have either not been investigated or very few studies exist in adolescents. For example, the Coronary Artery Risk Development in Young Adults (CARDIA) study reported a graded association between serum cotinine concentrations (a metabolite of exposure to tobacco) and the 15-year incidence of glucose intolerance ${ }^{(18)}$; yet no studies with younger groups exist. Similarly, in a small US study, levels of physical activity over an $8 \mathrm{~d}$ period were positively associated with efficient glucose metabolism in an intravenous glucose tolerance test ${ }^{(19)}$; but existing investigations of physical activity as a risk factor have tended to be small $^{(19)}$ or assessed activity levels over short periods ${ }^{(19-21)}$. It is also important to highlight that these associations have been estimated with incomplete adjustment for their mutual effects. This is important, as many are interrelated (e.g. obesity is associated with high SFA intake ${ }^{(22)}$ and low levels of physical activity ${ }^{(23)}$ ) and some foods high in both SFA and PUFA (e.g. margarine) may have opposing effects on insulin resistance ${ }^{(16)}$.

Against this background of a paucity of data on diet and the development of insulin resistance, we used data from the National Heart, Lung, and Blood Institute Growth and Health Study (NGHS), a 10-year study with adolescent girls. With concentrations of fasting blood glucose and insulin, objective assessments of BMI and tobacco exposure (serum cotinine) and detailed questions on the intake of different fats, fibre, sodium and alcohol, this cohort afforded us the opportunity to examine a range of risk factors for the development of insulin resistance. We sought to identify the independent effects of changes in risk factors, to address some of the weaknesses of the research with adults and provide information on viable targets for prevention in adolescence.

\section{Materials and methods}

We conducted secondary analyses of the NGHS. The NGHS was conducted according to the guidelines laid down in the Declaration of Helsinki and all procedures involving human subjects/patients were approved by the Institutional Review Boards at all participating centres (the Children's Medical Center, Cincinnati, OH; Westat, Inc., Rockville, MD; and the University of California, Berkeley, CA). Written informed consent was obtained from all participants and their parents.

A complete description of NGHS procedures, including the measurement of glucose and insulin ${ }^{(24)}, \mathrm{BMI}^{(25,26)}$, nutrient intake ${ }^{(27,28)}$ and physical activity ${ }^{(29)}$, have been previously reported. Fasting blood samples were collected at ages 9 or 10 years (year 1), 16 or 17 years (year 7) and 18 or 19 years (year 10). Race was defined by selfreport and eligible participants had to declare themselves as 'black' or 'white'. We restricted our analysis to ages 16-17 years and 18-19 years, as fasting blood samples and cotinine were not assessed at other ages.
The present analyses are based on a sample of girls with complete information on each risk factor $(\% \mathrm{~kJ}$ from SFA, \% kJ from MUFA, \% $\mathrm{kJ}$ from PUFA; \% $\mathrm{kJ}$ from carbohydrates; grams of: sucrose, starch, soluble fibre, insoluble fibre, sodium, alcohol; physical activity in MET-min/d (MET, metabolic equivalents of task); BMI; cotinine; smoking status), potential confounding variables (age at entry, race, level of parental education, and changes in height and menstrual status) and a fasting blood sample at ages 16-17 and 18-19 years. We used $t$ tests and $\chi^{2}$ tests to examine differences between continuous and categorical values, respectively, for girls who were and were not included in the final analytical sample.

Of the 2379 participants recruited at age 9-10 years, $1783(74 \cdot 9 \%)$ took part at ages $16-17$ and $18-19$ years when fasting blood samples were collected. Of these, $935(52 \cdot 4 \%)$ had fasting blood samples at ages 16-17 and 18-19 years and a concentration of serum cotinine determined at age 16-17 years. A total of 774 girls (43.4\%) provided valid estimates of all risk factors and potential confounders.

\section{Assessment of fasting blood glucose, insulin and insulin resistance}

Fasting serum insulin (competitive protein-binding RIA) and glucose concentrations were measured after an overnight fast ( $\geq 8 \mathrm{~h}$ ) at the Endocrine Laboratory of the Michigan Diabetes Research and Training Center (Ann Arbor, MI, USA) at age 16-17 years and at the University of Cincinnati/Children's Medical Center (Cincinnati, OH, USA) at age 18-19 years. Glucose was measured using the glucose oxidase method with the Hitachi 704 chemistry analyser (Roche Diagnostics, Indianapolis, IN, USA). Homeostasis model assessment of insulin resistance (HOMA-IR) was used as an index of insulin resistance ${ }^{(30)}$. HOMA-IR was chosen instead of fasting glucose:insulin or the quantitative insulin sensitivity check index (QUICKI), as HOMA-IR has better sensitivity and specificity in identifying adolescents with insulin sensitivity than these measures $^{(31)}$.

\section{Assessment of obesity}

BMI $\left(\mathrm{kg} / \mathrm{m}^{2}\right)$ was derived from measurements of height and weight. Height was measured to the nearest $0 \cdot 1 \mathrm{~cm}$, using custom-made stadiometers. Weight was measured to the nearest $0 \cdot 1 \mathrm{~kg}$ with calibrated Health-O-meter electronic scales (Sunbeam Products, Inc., Maitland, FL, USA). If the second measurement differed from the first by $>0.5 \mathrm{~cm}$ for height and $0.3 \mathrm{~kg}$ for weight, the same examiner took a third measurement. The mean of the two or three measurements was used for analysis. Obesity was coded using the International Obesity Taskforce cut-off point at 16-17 years $\left(\mathrm{BMI}>29 \cdot 43 \mathrm{~kg} / \mathrm{m}^{2}\right)^{(32)}$ and the WHO adult standard at $18-19$ years $\left(\mathrm{BMI} \geq 30 \cdot 0 \mathrm{~kg} / \mathrm{m}^{2}\right)^{(33)}$. The International Obesity Taskforce criterion was applied, rather than other alternatives (e.g. $\geq 95$ th percentile on the 
US Centers for Disease Control and Prevention growth charts), because it was designed to identify age-appropriate cut-off points which pass through the commonly applied WHO adult standard; thus facilitating comparisons with adult studies.

\section{Assessment of exposure to tobacco}

Exposure to tobacco smoke was assessed at age 16-17 years using serum cotinine, a metabolite of nicotine. Each sample was analysed at the American Health Foundation (Valhalla, NY, USA) using a modification of the method by Langone et $a l^{(34,35)}$ As cotinine concentrations showed strong negative skewness, exposure was re-coded as 0 (no exposure) $v$. $>0 \mathrm{ng} / \mathrm{ml}$. Information on smoking status (non-smoker or smoker) was also obtained by questionnaire at ages 16-17 and 18-19 years. Self-reports were used to identify if girls had started or stopped smoking by 18-19 years.

\section{Dietary assessment}

Nutrient intake was assessed using a food diary on three consecutive days (including one day in the weekend and two weekdays) ${ }^{(28)}$. Briefly, each girl was provided with measuring cups, spoons, rulers, a portion-size guide and age-appropriate instructions to record all food and drink, as well as the time of intake. The completed food diaries were reviewed individually by certified dietitians (all within $15 \mathrm{~d}$ of being completed) and supplementary information was sought using standard probes to clarify incomplete responses ${ }^{(28)}$. Each diary was reviewed in depth by a nutritionist through an interview and any inconsistencies or questionable items were clarified. Default values adapted from the Minnesota Nutrition Coordinating Center were used for missing information on food amounts or preparation methods. To minimize the use of defaults, staff had a notebook of labels and label pictures to help girls describe foods.

Nutrient intake was analysed using the Nutrient Data System software developed by the University of Minnesota ${ }^{(36)}$. Means for macronutrients and dietary components were averaged across the $3 \mathrm{~d}$ of diet records for each participant. In a validation study, this $3 \mathrm{~d}$ diary had a lower percentage of absolute errors, missing foods (i.e. observed food items not reported) and phantom foods (i.e. reported food items not observed) than a $5 \mathrm{~d}$ recall and a $24 \mathrm{~h}$ recall when compared with intake recorded unobtrusively, suggesting it provided a valid measure of dietary intake.

\section{Assessment of physical activity, developmental status and other demographic variables}

Habitual physical activity was assessed using a $3 \mathrm{~d}$ activity diary, in tandem with the $3 \mathrm{~d}$ food record ${ }^{(29)}$. Mean energy expenditure was represented as the number of minutes engaged in different metabolic equivalent (MET) activities across the day, expressed as MET-min/d.
Information on the occurrence of/date of menstrual periods and age was obtained by questionnaire at ages $16-17$ and 18-19 years ${ }^{(37)}$. The highest level of parental education was collected at study entry from parents (or guardians) and taken as the maximum level of education achieved by either parent. Maximum parental education was categorized into: high school or less; college (some post high-school education); and college ( $\geq 4$ years).

\section{Statistical methods}

Means and standard deviations were calculated for continuous variables and proportions were used for categorical variables. We used two-sided $t$ tests to examine changes in risk factors between ages 16-17 and 18-19 years and the Wilcoxon signed rank test for changes in continuous variables that were skewed. The associations between risk factors (at age 16-17 years), and changes $(\Delta)$ in risk factors (between the ages of 16-17 and 18-19 years), with changes in fasting glucose, fasting insulin and HOMA-IR values were assessed using three multiple linear regression models. Each linear regression model included changes in all risk factors between 16-17 and 18-19 years and baseline values at 16-17 years. Models were also adjusted for the covariates of age, race, changes between 16-17 and 18-19 years in height and menstrual status, and parental education at entry as potential confounding factor. As the NGHS employed a nested design, we used a random-effects model with recruitment centre included as a random effect with robust standard errors to adjust for the effect of clustering.

We compared the distribution of study variables between our analytical sample and those who participated at ages 16-17 and 18-19 years but were excluded due to missing data. Girls in the excluded group were less likely to have parents who had attended $\geq 4$ years of college than those in the analytical sample $(32 \cdot 0 \% \mathrm{v}$. $41.5 \%, P<0.001)$; they were also less likely to start smoking by $18-19$ years $(11 \cdot 5 \% v .16 \cdot 1 \%, P=0 \cdot 002)$; and had a slightly higher intake of MUFA (mean 12.74 (SD 2.97) \% v. $12 \cdot 25(\mathrm{SD} 3 \cdot 20) \%, P=0.002)$ and SFA (mean 12.37 (sD 3.17) \% v. $11.92(\mathrm{sD} 3 \cdot 36) \%, P=0 \cdot 005)$ as a percentage of energy, but a lower percentage of their energy intake came from carbohydrates (mean 52.72 (sD 8.31) \% v. 53.88 (sD 8.88) \%, $P=0 \cdot 007$ ). There were no differences between the groups in glucose, insulin and HOMA-IR levels, or other variables.

We conducted sensitivity analyses to explore the potential effect of excluding participants at age 16-17 or 18-19 years who had a fasting blood glucose $\geq 100-126 \mathrm{mg} / \mathrm{dl}$ indicative of IFG or $\geq 126 \mathrm{mg} / \mathrm{dl}$ as a diagnosis of T2DM ${ }^{(38)}$ (2012 definitions of the American Diabetes Association (ADA)), to focus on the role of these risk factors in prevention. All analyses were conducted using the Stata version 10 statistical software package. 


\section{Results}

Characteristics of participants at ages 16-17 and 18-19 years are summarized in Tables 1 and 2. At baseline, most girls were around 16 years of age (mean 16.00 (SD 0.56) years), had a BMI in the normal range (mean 23.76 (SD 5.43) $\mathrm{kg} / \mathrm{m}^{2}$; using the International Obesity Taskforce criterion) and fasting glucose levels which did not suggest IFG or T2DM (mean 76.58 (sD 17.30) mg/dl; using the 2012 ADA definition). Table 1 shows girls were more likely to become obese than normal weight $(6 \cdot 5 \% v .1 \cdot 4 \%, P<0 \cdot 001)$, start smoking than stop $(16 \cdot 1 \% v .3 \cdot 4 \%, P<0 \cdot 001)$, and all girls had started menstruating by age $18-19$ years.

Table 2 shows that between the ages of 16-17 and 18-19 years, concentrations of fasting blood glucose increased significantly (mean 76.58 (SD 17.30) mg/dl $v$. $89 \cdot 21$ (sD 39.12) $\mathrm{mg} / \mathrm{dl}, P<0 \cdot 001$ ), concentrations of fasting blood insulin decreased significantly (mean $13 \cdot 29$ (sD 10.76) $\mu \mathrm{IU} / \mathrm{ml} v \cdot 10 \cdot 62(\mathrm{sD} 9 \cdot 17) \mu \mathrm{IU} / \mathrm{ml}, P<0 \cdot 001$ ), and a slight change was found in HOMA-IR values (mean $2 \cdot 62$ (SD 3.38) v. 2.39 (SD 2.58), $P=0.096$ ). The average percentage of energy from fat decreased significantly (specifically $\% \mathrm{~kJ}$ from SFA and MUFA, $P=0 \cdot 001$ ) and an increase was observed in the percentage of energy from carbohydrates $(P<0 \cdot 001)$; grams of soluble fibre, alcohol, sodium $(P<0 \cdot 001)$, insoluble fibre $(P=0 \cdot 014)$ and starch also increased $(P=0 \cdot 015)$.

Table 3 shows that among dietary variables, after adjustment for potential confounders, the $\% \mathrm{~kJ}$ from PUFA at age $16-17$ years $(\beta=-0 \cdot 84,95 \% \mathrm{CI}-1 \cdot 51,-0 \cdot 18$; $P<0 \cdot 05)$ and increases between ages $16-17$ and 18-19 years in the $\% \mathrm{~kJ}$ from PUFA $(\beta=-0 \cdot 58,95 \% \mathrm{CI}-1 \cdot 09$, $-0.07 ; P<0.05)$ and grams of soluble fibre $(\beta=-0.93$, $95 \% \mathrm{CI}-1 \cdot 73,-0 \cdot 13 ; P<0 \cdot 05)$ were inversely associated with a change in fasting blood insulin concentrations between 16-17 and 18-19 years. Replicating these findings, increases in the $\% \mathrm{~kJ}$ from PUFA $(\beta=-3 \cdot 33,95 \%$ CI $-6 \cdot 28,-0.39 ; P<0.05)$ and grams of soluble fibre $(\beta=-5 \cdot 20,95 \%$ CI $-9 \cdot 81,-0.59 ; P<0.05)$ were also associated with a decrease in HOMA-IR values. The other dietary variables were not associated with changes in insulin resistance at conventional levels.

Serum cotinine concentrations at age 16-17 years were associated with a large increase in the concentration of fasting blood glucose between the ages of $16-17$ and 18-19 years $(\beta=15 \cdot 43,95 \%$ CI $6 \cdot 09,24 \cdot 77 ; P<0 \cdot 001)$, whereas changes in smoking status were not. Transitioning over the 3-year follow-up period into obesity was positively associated with a large increase in fasting blood insulin $(\beta=6 \cdot 34,95 \%$ CI $2 \cdot 78,9 \cdot 91 ; P<0 \cdot 001)$ and HOMA-IR levels $(\beta=28 \cdot 77,95 \%$ CI $8 \cdot 13,49 \cdot 40 ; P<0 \cdot 01)$. Physical activity was not associated with insulin resistance.

To explore if the results were confounded by the inclusion of girls with pre-existing or developing insulin resistance, we excluded those with IFG (16-17 years: $n 6$, $0 \cdot 78 \%$; $18-19$ years: $n 40,5 \cdot 16 \%)$ or T2DM (16-17 years: $n 4,0 \cdot 51 \%$; $18-19$ years: $n 5,0 \cdot 65 \%$ ) from the analyses. Following these exclusions, results were very similar with no loss in the strength of effects and slight reduction in precision (data not tabulated); we therefore present the results for the entire analytical cohort.

\section{Discussion}

In the present study into the development of insulin resistance in adolescence, improvements in fasting insulin and HOMA-IR levels were associated with increases in the intake of PUFA and soluble fibre, whereas exposure to tobacco smoke was associated with increases in concentrations of

Table 1 Categorical measures in girls with assessments on glucose, insulin and HOMA-IR by modifiable risk factors at ages 16-17 and $18-19$ years $(n 774)$, NHLBI Growth and Health Study

\begin{tabular}{|c|c|c|c|}
\hline Categorical measure & Category & $n$ & $\%$ \\
\hline \multirow[t]{2}{*}{ Race } & White & 389 & $50 \cdot 3$ \\
\hline & Black & 385 & $49 \cdot 7$ \\
\hline \multirow{3}{*}{ Highest level of parental education } & High school or less & 150 & $19 \cdot 4$ \\
\hline & College (some post high-school education) & 303 & $39 \cdot 1$ \\
\hline & College ( $\geq 4$ years) & 321 & $41 \cdot 5$ \\
\hline \multirow[t]{2}{*}{ Menstruating at $16-17$ years } & Yes & 726 & $93 \cdot 8$ \\
\hline & No & 48 & $6 \cdot 2$ \\
\hline \multirow{2}{*}{ Menstruating at $18-19$ years } & Yes & 774 & $100 \cdot 0$ \\
\hline & No & 0 & $0 \cdot 0$ \\
\hline \multirow[t]{2}{*}{ Cotinine } & 0 & 685 & $88 \cdot 5$ \\
\hline & $>0(\mathrm{ng} / \mathrm{ml})$ & 89 & $11 \cdot 5$ \\
\hline \multirow[t]{2}{*}{ Smoking status at $16-17$ years } & Smoker & 125 & $16 \cdot 1$ \\
\hline & Non-smoker & 648 & $83 \cdot 5$ \\
\hline \multirow[t]{2}{*}{ Smoking status at $18-19$ years } & Smoker & 225 & $29 \cdot 1$ \\
\hline & Non-smoker & 548 & $70 \cdot 7$ \\
\hline \multirow[t]{2}{*}{ Obese at $16-17$ yearst } & Obese & 107 & $13 \cdot 8$ \\
\hline & Not obese & 667 & $86 \cdot 2$ \\
\hline \multirow[t]{2}{*}{ Obese at $18-19$ yearst } & Obese & 146 & $18 \cdot 9$ \\
\hline & Not obese & 628 & $81 \cdot 1$ \\
\hline
\end{tabular}

HOMA-IR, homeostasis model assessment of insulin resistance; NHLBI, National Heart, Lung, and Blood Institute.

tAge- and sex-standardized cut-off points of the International Obesity Taskforce applied. 
fasting glucose, and becoming obese predicted large increases in the concentration of insulin and HOMA-IR. These results are consistent with prospective cohorts which have assessed PUFA intake in middle-aged women ${ }^{(16)}$ and dietary fibre ${ }^{(12)}$, obesity ${ }^{(39)}$ and tobacco exposure in adults $^{(18)}$. Our findings extend these results by suggesting that these associations operate independently in girls in late adolescence, after adjusting for variations in macronutrient intake, habitual physical activity and pubertal onset. We also showed that these associations were unaltered after excluding girls who had or were developing IFG and T2DM, suggesting these factors may be viable targets for prevention.

Consistent with previous findings, we found that diets high in soluble fibre were associated with improvements in insulin and HOMA-IR levels ${ }^{(12,39)}$. In the 10-year follow-up of the CARDIA study, there was an inverse relationship between dietary fibre and the risk of metabolic syndrome $(\mathrm{OR}=0 \cdot 66,95 \% \text { CI } 0 \cdot 53,0 \cdot 80)^{(12)}$. Our findings add to the growing body of epidemiological data linking high-fibre diets with lower insulin resistance ${ }^{(40,41)}$; although there is a need for randomized evaluation of the effect of these diets in adolescence.

Epidemiological data on the influence of dietary fats on insulin resistance in adolescence are sparse. In a previous analysis of the present cohort, an interaction between the percentage of energy from fat and HOMA-IR values at age 9-10 years was associated with an increased risk of IFG and T2DM at 18-19 years ${ }^{(42)}$. After adjustment for different types of fats, we found an inverse association between insulin resistance and PUFA intake. This is consistent with the findings from trials among adults with diabetes showing improved insulin resistance was associated with randomization to a diet with a high PUFA:SFA ratio $^{(43)}$ or high linoleic acid content ${ }^{(44)}$.

Our finding that increases in insulin and HOMA-IR were associated with becoming obese is consistent with crosssectional $^{(39)}$ and prospective studies ${ }^{(8,42)}$. Closely replicating our method of modelling obesity, a recent Israeli cohort found increases in BMI between 17 and 34 years were associated with an increased risk of T2DM, even after adjusting for baseline $\mathrm{BMI}^{(45)}$; and an intervention with adolescent girls demonstrated that a reduction in insulin resistance occurred after weight loss ${ }^{(46)}$. The data presented here suggest that increases in BMI can adversely affect insulin resistance over shorter periods in adolescent girls.

To our knowledge, only one other prospective study has assessed the association between an objective measure of exposure to tobacco smoke and the development of metabolic risk ${ }^{(18)}$. In the CARDIA study, the 15 -year incidence of insulin resistance was $11.5 \%$ in non-smokers not exposed to environmental tobacco smoke, $14 \cdot 4 \%$ in former smokers, $17 \cdot 2 \%$ in non-smokers exposed to environmental tobacco smoke and $21 \cdot 8 \%$ among smokers. Interestingly, adjustment for waist-to-hip ratio did not alter this association, suggesting that this association, if causal, is not moderated by the effect of smoking on fat distribution. Our findings 
Table 3 Regression coefficients (95\% confidence intervals) for changes in glucose, insulin and HOMA-IR by modifiable risk factors (assessed at age 16-17 years) and change $(\Delta)$ in modifiable risk factors (between the ages of $16-17$ and $18-19$ years) in girls $(n 774)$, NHLBI Growth and Health Study

\begin{tabular}{|c|c|c|c|c|c|c|}
\hline & \multicolumn{2}{|c|}{ Glucose (mg/dl) } & \multicolumn{2}{|c|}{ Insulin ( $\mu \mathrm{IU} / \mathrm{ml})$} & \multicolumn{2}{|c|}{ HOMA-IR } \\
\hline & Coefficient & $95 \% \mathrm{Cl}$ & Coefficient & $95 \% \mathrm{Cl}$ & Coefficient & $95 \% \mathrm{Cl}$ \\
\hline \multicolumn{7}{|l|}{ Risk factors at $16-17$ years } \\
\hline Total energy $(\mathrm{kJ} / \mathrm{d})$ & -0.01 & $-0.01,0.01$ & -0.01 & $-0.01,0.01$ & -0.01 & $-0.01,0.01$ \\
\hline$\% \mathrm{~kJ}$ from SFA & $-0 \cdot 12$ & $-2 \cdot 18,1 \cdot 95$ & -0.48 & $-1 \cdot 11,0 \cdot 15$ & $-1 \cdot 20$ & $-4 \cdot 85,2 \cdot 45$ \\
\hline$\% \mathrm{~kJ}$ from MUFA & $1 \cdot 62$ & $-0 \cdot 95,4 \cdot 18$ & $0 \cdot 14$ & $-0.65,0.92$ & 0.28 & $-4 \cdot 25,4 \cdot 81$ \\
\hline$\% \mathrm{~kJ}$ from PUFA & $-2 \cdot 08$ & $-4 \cdot 25,0 \cdot 10$ & $-0 \cdot 84$ & $-1 \cdot 51,-0 \cdot 18^{*}$ & -3.59 & $-7 \cdot 43,0.25$ \\
\hline$\% \mathrm{~kJ}$ from carbohydrates & 0.01 & $-1 \cdot 13,1 \cdot 13$ & $-0 \cdot 15$ & $-0 \cdot 49,0 \cdot 19$ & -0.22 & $-2 \cdot 21,1 \cdot 77$ \\
\hline Sucrose (g) & -0.03 & $-0 \cdot 24,0 \cdot 20$ & 0.04 & $-0.03,0.10$ & $0 \cdot 26$ & $-0.13,0.65$ \\
\hline Starch $(g)$ & $0 \cdot 11$ & $-0.08,0.30$ & -0.01 & $-0.06,0.05$ & -0.04 & $-0 \cdot 38,0 \cdot 29$ \\
\hline Soluble fibre $(\mathrm{g})$ & -0.37 & $-3 \cdot 93,3 \cdot 20$ & -0.67 & $-1 \cdot 75,0 \cdot 42$ & $-4 \cdot 94$ & $-11 \cdot 24,1 \cdot 36$ \\
\hline Insoluble fibre $(\mathrm{g})$ & -0.35 & $-2 \cdot 24,1 \cdot 54$ & $0 \cdot 13$ & $-0.45,0.71$ & $0 \cdot 84$ & $-2 \cdot 49,4 \cdot 18$ \\
\hline Sodium (g) & $-2 \cdot 11$ & $-7 \cdot 75,3 \cdot 53$ & -0.23 & $-1 \cdot 95,1 \cdot 50$ & $2 \cdot 33$ & $-7 \cdot 64,12 \cdot 29$ \\
\hline Alcohol (g) & $-0 \cdot 32$ & $-2 \cdot 71,2 \cdot 08$ & -0.02 & $-0.75,0.72$ & $0 \cdot 13$ & $-4 \cdot 11,4 \cdot 36$ \\
\hline Physical activity (MET-min/d) & -0.01 & $-0.01,0.01$ & -0.01 & $-0.01,0.01$ & -0.01 & $-0.03,0.02$ \\
\hline BMI (IOTF: not obese $v$. obese) & 3.05 & $-5 \cdot 95,12 \cdot 04$ & -0.04 & $-2 \cdot 79,2 \cdot 70$ & $-6 \cdot 90$ & $-22 \cdot 79,8 \cdot 99$ \\
\hline Cotinine $0 v .>0 \mathrm{ng} / \mathrm{ml}$ & $15 \cdot 43$ & $6 \cdot 09,24 \cdot 77^{\star \star \star}$ & -0.36 & $-3 \cdot 21,2 \cdot 50$ & $1 \cdot 91$ & $-14 \cdot 59,18 \cdot 42$ \\
\hline \multicolumn{7}{|l|}{$\begin{array}{l}\text { Change in risk factors between ages of } \\
16-17 \text { and } 18-19 \text { years }\end{array}$} \\
\hline$\Delta$ Total energy $(\mathrm{kJ} / \mathrm{d})$ & -0.01 & $-0.01,0.01$ & -0.01 & $-0.01,0.01$ & -0.01 & $-0.01,0.01$ \\
\hline$\Delta \% \mathrm{~kJ}$ from SFA & 0.47 & $-1 \cdot 24,2 \cdot 18$ & -0.26 & $-0 \cdot 78,0 \cdot 26$ & 0.04 & $-2.98,3.06$ \\
\hline$\Delta \% \mathrm{~kJ}$ from MUFA & $-1 \cdot 30$ & $-3 \cdot 26,0.65$ & 0.07 & $-0.52,0.67$ & $-1 \cdot 30$ & $-4 \cdot 75,2 \cdot 16$ \\
\hline$\Delta \% \mathrm{~kJ}$ from PUFA & -1.04 & $-2 \cdot 70,0 \cdot 63$ & -0.58 & $-1 \cdot 09,-0.07^{\star}$ & $-3 \cdot 33$ & $-6 \cdot 28,-0 \cdot 39^{*}$ \\
\hline$\Delta \% \mathrm{~kJ}$ from carbohydrates & -0.26 & $-1 \cdot 08,0.56$ & -0.06 & $-0 \cdot 31,0 \cdot 20$ & -0.29 & $-1 \cdot 74,1 \cdot 16$ \\
\hline$\Delta$ Sucrose $(\mathrm{g})$ & $-0 \cdot 13$ & $-0.29,0.03$ & 0.01 & $-0.05,0.05$ & -0.07 & $-0 \cdot 35,0 \cdot 21$ \\
\hline$\Delta$ Starch (g) & 0.04 & $-0 \cdot 11,0 \cdot 18$ & 0.01 & $-0.04,0.05$ & -0.02 & $-0.27,0.23$ \\
\hline$\Delta$ Soluble fibre $(\mathrm{g})$ & $-0 \cdot 73$ & $-3 \cdot 33,1 \cdot 87$ & -0.93 & $-1 \cdot 73,-0 \cdot 13^{*}$ & $-5 \cdot 20$ & $-9 \cdot 81,-0.59^{\star}$ \\
\hline$\Delta$ Insoluble fibre $(\mathrm{g})$ & -0.03 & $-1 \cdot 40,1 \cdot 34$ & 0.26 & $-0.16,0.68$ & $1 \cdot 68$ & $-0 \cdot 74,4 \cdot 10$ \\
\hline$\Delta$ Sodium $(\mathrm{g})$ & $-1 \cdot 28$ & $-5 \cdot 19,2 \cdot 64$ & -0.75 & $-1.94,0.45$ & $-6 \cdot 04$ & $-12 \cdot 96,0 \cdot 88$ \\
\hline$\Delta$ Alcohol (g) & 0.36 & $-0 \cdot 08,0.80$ & -0.06 & $-0.20,0.07$ & -0.39 & $-1 \cdot 17,0 \cdot 39$ \\
\hline$\Delta$ Physical activity (MET-min/d) & -0.01 & $-0.01,0.01$ & -0.01 & $-0.01,0.01$ & 0.01 & $-0.02,0.01$ \\
\hline$\Delta \mathrm{BMl}$ (IOTF: normal $v$. become obese) & -0.05 & $-11 \cdot 73,11 \cdot 63$ & $6 \cdot 34$ & $2 \cdot 78,9 \cdot 91^{\star * \star}$ & $28 \cdot 77$ & $8 \cdot 13,49 \cdot 40^{\star *}$ \\
\hline$\Delta \mathrm{BMI}$ (IOTF: obese $v$. become normal) & $-13 \cdot 29$ & $-38 \cdot 67,12 \cdot 09$ & $-3 \cdot 30$ & $-11 \cdot 05,4 \cdot 45$ & $-16 \cdot 82$ & $-61 \cdot 67,28 \cdot 02$ \\
\hline$\Delta$ Smoking status (never $v$. start) & $-3 \cdot 43$ & $-11 \cdot 27,4 \cdot 42$ & $0 \cdot 75$ & $-1 \cdot 65,3 \cdot 14$ & $5 \cdot 74$ & $-22 \cdot 26,33.75$ \\
\hline$\Delta$ Smoking status (never $v$. give up) & $-11 \cdot 54$ & $-27 \cdot 39,4 \cdot 31$ & $1 \cdot 92$ & $-2 \cdot 92,6 \cdot 76$ & $5 \cdot 13$ & $-8 \cdot 74,18.99$ \\
\hline
\end{tabular}

HOMA-IR, homeostasis model assessment of insulin resistance; NHLBI, National Heart, Lung, and Blood Institute; MET, metabolic equivalents of task; IOTF, International Obesity Taskforce (age- and sex-standardized classification applied).

All models are adjusted for the following covariates: age at entry, race, change between the ages of 16-17 and 18-19 years in height and menstrual status, and confounder of parental education.

Significance of coefficient $(95 \% \mathrm{Cl}):{ }^{\star} P<0.05,{ }^{\star \star} P<0.01$, ${ }^{\star \star \star} P<0.001$.

replicate this result in a younger cohort of adolescent girls, and suggest that environmental tobacco smoke is associated with significant increases in fasting blood glucose, after adjusting for changes in smoking and weight status.

Changes in the volume of habitual physical activity were unrelated to insulin resistance. This contrasts with results from a prospective study ${ }^{(21)}$, which found small associations between the volume of activity (assessed using accelerometry) and HOMA-IR. That prospective study also showed stronger associations between improvements in insulin resistance and minutes engaged in moderate-to-vigorous physical activity than with overall activity levels ${ }^{(21)}$. Our failure to replicate these associations suggests that our selfreport measure might have not captured the true volume of activity; but also suggests that moderate-to-vigorous physical activity rather than overall volume of physical activity may be more closely related to changes in insulin resistance.

The use of an objective measure of environmental tobacco smoke exposure, the detailed nutritional profiling and the assessments of change in obesity, smoking status and physical activity, as well as other risk factors for insulin resistance, are major strengths of the present study. There are also some limitations. Cohort attrition and nonparticipation may have resulted in a less representative sample and participants were not randomly selected, thus the study results cannot be extrapolated to all adolescent girls. Second, we used fasting glucose and insulin values in the HOMA-IR equation to estimate insulin resistance, rather than the more accurate euglycaemic clamp ${ }^{(47)}$. Third, although the $3 \mathrm{~d}$ dietary diary was found to be more accurate than a $24 \mathrm{~h}$ recall or a $5 \mathrm{~d}_{\text {recall }}{ }^{(27)}$, it is unlikely to reflect actual dietary intake as well as a $7 \mathrm{~d}$ record.

\section{Conclusion}

Our analysis of the NGHS suggests that a number of small changes in lifestyle, namely the adoption of a diet high in soluble fibre and PUFA, in addition to avoidance of 
excess weight gain and tobacco, could substantially reduce insulin resistance in adolescent girls.

\section{Acknowledgements}

Sources of funding: The NGHS was supported by a grant from the National Heart, Lung, and Blood Institute (NHLBI; HL/DK71122). Participating NGHS centres included: the Children's Medical Center, Cincinnati, OH (Stephen R. Daniels, MD, Principal Investigator; John A. Morrison, PhD, Co-Investigator); Westat, Inc., Rockville, MD (George B. Schreiber, ScD, Principal Investigator; Ruth Striegel-Moore, $\mathrm{PhD}$, Co-Investigator); and the University of California, Berkeley, CA (Zak I. Sabry, PhD, Principal Investigator; Patricia B. Crawford, Dr PH, RD, Co-Investigator); the Maryland Medical Research Institute, Baltimore, MD (Bruce A. Barton, PhD, Principal Investigator) served as the data coordinating centre. Program Office: NHLBI (Eva Obarzanek, PhD, RD, Project Officer 1992-present; Gerald H. Payne, MD, Project Officer 1985-1991). The present work was undertaken at the Centre for the Development and Evaluation of Complex Interventions for Public Health Improvement, a United Kingdom Clinical Research Collaboration Public Health Research Centre of Excellence. Funding from the British Heart Foundation, Cancer Research UK, the Economic and Social Research Council (RES-590-28-0005), the Medical Research Council, the Welsh Assembly Government and the Wellcome Trust (WT087640MA), under the auspices of the UK Clinical Research Collaboration, is gratefully acknowledged. The present report is also research arising from a Career Development Fellowship (R.J.) supported by the National Institute for Health Research. The views expressed in this publication are those of the authors and not necessarily those of the UK National Health Service, the National Institute for Health Research or the Department of Health. Conflicts of interest: None of the authors had a conflict of interest. Authors' contributions: J.W. obtained the NGHS data; J.W. analysed the data; J.W., R.J. and J.L.T. interpreted the data, participated in the writing of the manuscript, and read and approved the final manuscript.

\section{References}

1. Danaei G, Finucane MM, Lu Y et al:; Global Burden of Metabolic Risk Factors of Chronic Diseases Collaborating Group (Blood Glucose) (2011) National, regional, and global trends in fasting plasma glucose and diabetes prevalence since 1980: systematic analysis of health examination surveys and epidemiological studies with 370 country-years and $2 \cdot 7$ million participants. Lancet $\mathbf{3 7 8}, 31-40$.

2. Everhart J, Pettitt DJ, Bennett P et al. (1992) Duration of obesity increases the incidence of NIDDM. Diabetes $\mathbf{4 1}$ 235-240.

3. Writing Group for the SEARCH for Diabetes in Youth Study Group; Dabelea D, Bell RA, D'Agostino RB Jr et al. (2007) Incidence of diabetes in youth in the United States. JAMA 297, 2716-2724.
4. Ogden CL, Carroll MD, Curtin LR et al. (2010) Prevalence of high body mass index in US children and adolescents, 2007-2008. JAMA 303, 242-249.

5. Sundblom E, Petzold M, Rasmussen F et al. (2008) Childhood overweight and obesity prevalences levelling off in Stockholm but socioeconomic differences persist. Int J Obes (Lond) 32, 1525-1530.

6. Kipping RR, Jago R \& Lawlor DA (2008) Obesity in children. Part 1: epidemiology, measurement, risk factors, and screening. BMJ 337, 922-927.

7. Han JC, Lawlor DA \& Kimm SY (2010) Childhood obesity. Lancet 375, 1737-1748.

8. Pan Y \& Pratt CA (2008) Metabolic syndrome and its association with diet and physical activity in US adolescents. J Am Diet Assoc 108, 276-286.

9. Morrison JA, Glueck CJ, Horn PS et al. (2010) Childhood predictors of adult type 2 diabetes at 9- and 26-year follow-ups. Arch Pediatr Adolesc Med 164, 53-60.

10. Franks PW, Hanson RL, Knowler WC et al. (2007) Childhood predictors of young-onset type 2 diabetes. Diabetes 56, 2964-2972.

11. Ludwig DS, Pereira MA, Kroenke CH et al. (1999) Dietary fiber, weight gain, and cardiovascular disease risk factors in young adults. JAMA 282, 1539-1546.

12. Pereira MA, Jacobs DR Jr, Van Horn L et al. (2002) Dairy consumption, obesity, and the insulin resistance syndrome in young adults. JAMA 287, 2081-2089.

13. Schulze MB, Schulz M, Heidemann C et al. (2007) Fiber and magnesium intake and incidence of type 2 diabetes: a prospective study and meta-analysis. Arch Intern Med 167, 956-965.

14. Parillo M, Rivellese AA, Ciardullo AV et al. (1992) A high-monounsaturated-fat/low-carbohydrate diet improves peripheral insulin sensitivity in non-insulin-dependent diabetic patients. Metabolism 41, 1373-1378.

15. Karlström BE, Järvi AE, Byberg L et al. (2011) Fatty fish in the diet of patients with type 2 diabetes: comparison of the metabolic effects of foods rich in $n-3$ and $n-6$ fatty acids. Am J Clin Nutr 94, 26-33.

16. Salmeron J, Hu FB, Manson JE et al. (2001) Dietary fat intake and risk of type 2 diabetes in women. Am J Clin Nutr 73, 1019-1026.

17. Garg A (1998) High-monounsaturated-fat diets for patients with diabetes mellitus: a meta-analysis. Am J Clin Nutr 67, 3 Suppl., 577S-582S.

18. Houston TK (2006) Active and passive smoking and development of glucose intolerance among young adults in a prospective cohort: CARDIA study. BMJ 332, 1064-1069.

19. Thomas AS, Greene LF, Ard JD et al. (2009) Physical activity may facilitate diabetes prevention in adolescents. Diabetes Care 32, 9-13.

20. Henderson M, Gray-Donald K, Mathieu ME et al. (2012) How are physical activity, fitness, and sedentary behavior associated with insulin sensitivity in children? Diabetes Care 35, 1272-1278.

21. Jago R, Wedderkopp N, Kristensen PL et al. (2008) Six-year change in youth physical activity and effect on fasting insulin and HOMA-IR. Am J Prev Med 35, 554-560.

22. Gillis LJ, Kennedy LC, Gillis AM et al. (2002) Relationship between juvenile obesity, dietary energy and fat intake and physical activity. Int J Obes Relat Metab Disord 26, 458-463.

23. Riddoch CJ, Leary SD, Ness AR et al. (2009) Prospective associations between objective measures of physical activity and fat mass in 12-14 year old children: the Avon Longitudinal Study of Parents and Children (ALSPAC). BMJ 339, b4544.

24. Morrison JA, Glueck CJ \& Wang P (2009) Preteen insulin levels interact with caloric intake to predict increases in obesity at ages 18 to 19 years: a 10 -year prospective study of black and white girls. Metabolism 59, 718-727. 
25. Kimm SY, Glynn NW, Obarzanek E et al. (2005) Relation between the changes in physical activity and body-mass index during adolescence: a multicentre longitudinal study. Lancet 366, 301-307.

26. Kimm SY, Obarzanek E, Barton BA et al. (1996) Race, socioeconomic status, and obesity in 9- to 10-year-old girls: the NHLBI Growth and Health Study. Ann Epidemiol 6, 266-275.

27. Crawford PB, Obarzanek E, Morrison J et al. (1994) Comparative advantage of 3-day food records over 24-hour recall and 5-day food frequency validated by observation of 9- and 10-year-old girls. J Am Diet Assoc 94, 626-630.

28. Obarzanek E, Schreiber GB, Crawford PB et al. (1994) Energy intake and physical activity in relation to indexes of body fat: the National Heart, Lung, and Blood Institute Growth and Health Study. Am J Clin Nutr 60, 15-22.

29. Kimm SY, Glynn NW, Kriska AM et al. (2000) Longitudinal changes in physical activity in a biracial cohort during adolescence. Med Sci Sports Exerc 32, 1445-1454.

30. Matthews DR, Hosker JP, Rudenski AS et al. (1985) Homeostasis model assessment: insulin resistance and $\beta$-cell function from fasting plasma glucose and insulin concentrations in man. Diabetologia 28, 412-419.

31. Keskin M, Kurtoglu S, Kendirci M et al. (2005) Homeostasis model assessment is more reliable than the fasting glucose/ insulin ratio and quantitative insulin sensitivity check index for assessing insulin resistance among obese children and adolescents. Pediatrics 115, e500-e503.

32. Cole TJ, Bellizzi MC, Flegal KM et al. (2000) Establishing a standard definition for child overweight and obesity worldwide: international survey. BMJ 320, 1240-1243.

33. World Health Organization (2000) Obesity: Preventing and Managing the Global Epidemic. Report of a WHO Consultation. WHO Technical Report Series no. 894. WHO: Geneva.

34. Langone JJ, Gjika HB \& Van Vunakis H (1973) Nicotine and its metabolites. Radioimmunoassays for nicotine and cotinine. Biochemistry 12, 5025-5030.

35. Haley NJ, Axelrad CM \& Tilton KA (1983) Validation of self-reported smoking behavior: biochemical analyses of cotinine and thiocyanate. Am J Public Health 73, 1204-1207.

36. Schakel SF, Sievert YA \& Buzzard IM (1988) Sources of data for developing and maintaining a nutrient database. $J \mathrm{Am}$ Diet Assoc 88, 1268-1271.
37. Kimm SY, Barton BA, Obarzanek E et al. (2002) Obesity development during adolescence in a biracial cohort: the NHLBI Growth and Health Study. Pediatrics 110, e54.

38. American Diabetes Association (2011) Diagnosis and classification of diabetes mellitus. Diabetes Care 35, Suppl. 1, S64-S71.

39. Pan Y \& Pratt CA (2008) Metabolic syndrome and its association with diet and physical activity in US adolescents. J Am Diet Assoc 108, 276-286.

40. McKeown NM, Meigs JB, Liu S et al. (2004) Carbohydrate nutrition, insulin resistance, and the prevalence of the metabolic syndrome in the Framingham Offspring Cohort. Diabetes Care 27, 538-546.

41. Salmeron J, Manson JE, Stampfer MJ et al. (1997) Dietary fiber, glycemic load, and risk of non-insulin-dependent diabetes mellitus in women. JAMA 277, 472-477.

42. Morrison JA, Glueck CJ, Horn PS et al. (2008) Pre-teen insulin resistance predicts weight gain, impaired fasting glucose, and type 2 diabetes at age 18-19 y: a 10-y prospective study of black and white girls. Am J Clin Nutr 88, 778-788.

43. Heine R, Mulder C, Popp-Snijders C et al. (1989) Linoleicacid-enriched diet: long-term effects on serum lipoprotein and apolipoprotein concentrations and insulin sensitivity in noninsulin-dependent diabetic patients. Am J Clin Nutr $\mathbf{4 9}$, 448-456.

44. Houtsmuller A, van Hal-Ferwerda J, Zahn K et al. (1980) Favourable influences of linoleic acid on the progression of diabetic micro- and macroangiopathy. Ann Nutr Metabol 24, 105-118.

45. Tirosh A, Shai I, Afek A et al. (2011) Adolescent BMI trajectory and risk of diabetes versus coronary disease. $N$ Engl J Med 364, 1315-1325.

46. Nassis GP, Papantakou K, Skenderi K et al. (2005) Aerobic exercise training improves insulin sensitivity without changes in body weight, body fat, adiponectin, and inflammatory markers in overweight and obese girls. Metabolism 54, 1472-1479.

47. Schwartz B, Jacobs DR Jr, Moran A et al. (2008) Measurement of insulin sensitivity in children: comparison between the euglycemic-hyperinsulinemic clamp and surrogate measures. Diabetes Care 31, 783-788. 